\title{
Long Non-Coding RNA Expression Profiling in Obesity Mice with Folic Acid Supplement
}

\author{
Feifei Ma ${ }^{a}$ Wei Lib Renqiao Tang ${ }^{b}$ Zhuo Liu ${ }^{a}$ Shengrong Ouyang ${ }^{a}$ Dingding Cao $^{a}$ \\ Yuanyuan Lia Jianxin $\mathrm{Wu}^{\mathrm{a}, \mathrm{b}}$ \\ aDepartment of Biochemistry, Capital Institute of Pediatrics, Beijing, 'braduate School, Chinese \\ Academy of Medical Science, Beijing, China
}

\section{Key Words}

LncRNAs • Expression profile $\bullet$ Gene $・$ Ontology $・$ Pathway $\bullet$ Co-expression

\begin{abstract}
Background/Aims: Obesity is a major contributor to the growing prevalence of metabolic and cardiovascular diseases. This study was designed to investigate the effect of folic acid (FA) on obese mice by detecting the genome-wide expression profile of IncRNAs and mRNAs in the heart. Methods: Heart samples were collected from mice fed with standard diet (SD), highfat diet (HFD) and high-fat diet with FA intake (HFDF). LncRNAs and mRNAs between HFD and HFDF group were analyzed by IncRNA microarray. Nine IncRNAs and mRNAs were validated using quantitative reverse transcription polymerase chain reaction (qRT-PCR). Bioinformatics prediction was used to investigate the potential function of these differentially expressed IncRNAs. Co-expresson analysis was used to determine the transcriptional regulatory relationship of differentially expressed IncRNAs and mRNAs between two groups. Results: The expression of 58,952 IncRNAs and 20,145 mRNAs in HFD and HFDF groups was profiled by using microarrays. Gene Ontology and pathway analyses indicated that the biological functions of differentially expressed mRNAs were related to inflammation, energy metabolism, and cell differentiation. Co-expression networks composed of IncRNAs and mRNAs were also constructed to investigate the potential regulatory roles of differentially expressed IncRNAs on mRNAs. LncRNAs, namely, NONMMUT033847, NONMMUT070811, and NONMMUT015327, were validated through $\mathrm{qRT}-\mathrm{PCR}$, and these IncRNAs may be important factors regulating inflammation, energy metabolism, and cell differentiation. The expression levels of Dnajb1, Egr2, Hba-a1, Il13, Cxcl2, and Tnfsf9 were significantly different between HFD and HFDF. Conclusions: Results suggested that FA may improve the cardiovascular function of obesity and contribute to those IncRNAs associated with inflammation and cell differentiation. In a nutshell, the present study identified a panel of IncRNAs and mRNAs that may be potential biomarkers or drug targets relevant to the high-fat diet related obesity.
\end{abstract}

(C) 2017 The Author(s)

Published by S. Karger AG, Basel

Jianxin Wu

KARGER
Department of Biochemistry, Capital Institute of Pediatrics, Road 2, Yabao, Beijing 100020, (China)

E-Mail cipbiolab@163.com 


\section{Cellular Physiology Cell Physiol Biochem 2017;42:416-426 \\ \begin{tabular}{l|l} 
DOI: 10.1159/000477486 & and Biochemistry \\
Published online: May 29, 2017 & $\begin{array}{l}\text { O 2017 The Author(s). Published by S. Karger AG, Basel } \\
\text { www.karger.com/cpb }\end{array}$
\end{tabular} \\ Ma et al.: LncRNA Expression Profile Analysis of Obesity with Folic Acid Supplement}

\section{Introduction}

Recent obesity epidemic is a major contributor to the increasing prevalence of metabolic and cardiovascular diseases [1]. In many chronic inflammatory diseases, genetic and environmental factors are essential for the development of obesity and its associated diseases [2, 3]. Folic acid (FA) supplement can effectively reduce the homocysteine levels and insulin resistance of obese children and consequently prevent obesity-related complications, including cardiovascular and metabolic disorders [4]. Food fortified with FA also helps decrease the birth prevalence of specific congenital heart defects (CHDs) [5].

The overexpression of interferon beta, an immune-modulating cytokine, likely attenuates high-fat diet (HFD)-induced adipose inflammation and protect animals against obesity development [6]. Eicosapentaenoic acid (EPA), an omega-3 fatty acid, improves the regenerative capacity of mouse skeletal muscle cells exposed to saturated fat and inflammation [7]. Therefore, obesity is associated with chronic low-grade inflammation, and inflammatory responses can induce detrimental metabolic effects. In obesity, chronic low-grade inflammation occurs in many organs, including, but not limited to, white adipose tissue (WAT), brown adipose tissue, pancreas, liver, brain, muscle, and intestines [8] [9].

Genome-wide transcriptional studies have indicated that approximately $1 \%$ of the human genome produces biologically significant RNA transcripts, whereas a much larger proportion of the genome is transcribed into non-coding RNAs (ncRNAs) [10,] [11], which are non-protein-coding transcripts longer than 200 nucleotides [12] and are possibly involved in the regulation of various molecular and cellular functions. Long non-coding RNAs (lncRNAs) are widely distributed in the human genome. More than $90 \%$ of the human genome is composed of non-coding RNAs [13]. Changes in the amount of IncRNAs can induce aberrant gene expression that contributes to various disease states and biological functions [14]. Thus far, 5,446 IncRNA genes have been identified in the human genome. However, the functions of these genes remain unclear. Therefore, the co-expression of lncRNAs and mRNA should be analyzed to help predict their functional roles in disease development as a foundation for further functional and mechanistic studies. IncRNAs common to white and brown fat are essential for adipogenesis [15]. For instance, lnc-RAP1 (Firre) is exclusively nuclear and interactive with the nuclear matrix factor hnRNP $U$ to mediate transchromosomal interactions between loci encoding adipogenic factors [16]. Differentially expressed circulating lncRNAs and mRNAs have been identified through microarray analysis between obese and non-obese human subjects [17]. Nevertheless, IncRNA biomarkers have yet to be identified in the heart of an obese individual.

In this study, the expression patterns of IncRNAs and mRNAs in the heart of mice fed with HFDF and HFD were demonstrated and validated through quantitative reverse transcriptionpolymerase chain reaction (qRT-PCR). Gene-lncRNA co-expression networks were further constructed to determine interaction patterns among genes with their related co-expressed lncRNAs. Our results suggested that FA might significantly affect the cardiovascular function of obesity.

\section{Materials and Methods}

Ethics Statement

Male wild-type (WT) mice in a C57BL/6 background were bred and maintained in the Laboratory of Animal Experiments at the Capital Institute of Pediatrics, Beijing China. The study was approved by the Ethical Committee for the Capital Institute of Pediatrics.

Animal Models

C57BL/6 background mice were purchased from HFK Bioscience Company. All of the mice used in the experiment were within 3 weeks old, maintained under specific pathogen-free conditions, and handled according to the animal welfare regulations of the Capital Institute of Pediatrics. Experimental procedures 


\section{Cellular Physiology Cell Physiol Biochem 2017;42:416-426 \begin{tabular}{l|l|} 
and Biochemistry Published 10.1159/000477486 & $\begin{array}{l}\text { C } 2017 \text { The Author(s). Published by S. Karger AG, Basel } \\
\text { www.karger.com/cpb }\end{array}$
\end{tabular} \\ Ma et al.: LncRNA Expression Profile Analysis of Obesity with Folic Acid Supplement}

were approved by the Animal Subjects Committee of the Capital Institute of Pediatrics. Male mice were randomly divided into three treatment groups ( $\mathrm{n}=15$ each): WT with HFD feeding and WT with HFDF feeding compared with WT with SD feeding. The mice were fed for 12 weeks. In this procedure, 20 mg of FA was dissolved in $1 \mathrm{~kg}$ of water. The body weight of each group of mice was monitored weekly. For intraperitoneal glucose tolerance testing, mice were fasted overnight and then subjected to intraperitoneal injection with glucose (2.0 $\mathrm{gg}-1$ of body weight) at the end of the experiment. Venouse blood was subsequently drawn by tail clipping at $0,15,30,60,120 \mathrm{~min}$. Blood glucose levels were measured with Accu-Chek giucometers (Roche Applied Science, Penzberg, Germay). Plasma cytokine and adipokine levels were measured using Milliplex Mouse Serum Cytokine and Adipokine Kits (Millipore Corp, Billerica, MA) on the Luminex IS 100 system (Luminex Corp, Austin, TX), as per the manufacturer's instructions.

\section{Preparation of array hybridization}

SBC 4x180K mouse lncRNA microarrays were custom-designed by using Agilent eArray according to the manufacturer's recommendations (https://earray.chem.agilent.com/earray). The microarray contained 20,145 mRNA probes and 58,952 lncRNA probes. The IncRNA sequence was derived from four databases, namely GENCODE v21, Ensembl, Noncode v4, and UCSC. After the labeled cRNAs were purified, each slide was hybridized and washed according to the manufacturer's instructions (Agilent Technologies). Raw data were normalized with quantile algorithm and limma packages in R. Differentially expressed lncRNAs and mRNAs were identified in terms of p-value and fold change. Experiments and analyses were performed by Shanghai Biotechnology Corporation.

\section{Quantitative real-time PCR}

Total RNA was extracted from mice hearts using TRIzol reagent (Invitrogen, USA) and then reversetranscribed with a high-capacity RNA-to-cDNA kit (Invitrogen, USA) according to the manufacturer's recommendations. The expression of significantly different IncRNAs and mRNAs in all of the subjects included in this study was determined through real-time PCR with SYBR Select Master Mix (Invitrogen, USA), and GAPDH was used as an internal control. For quantitative results, the expression of each lncRNA was represented as fold change by using 2- $\Delta \Delta \mathrm{Ct}$ methods. Differences in the lncRNA expression between HFDF and HFD were analyzed with Student's t-test. $P<0.05$ was considered significant. The primers used in this study are listed in Table 1.

\section{Functional group analysis}

Gene Ontology (GO) terms were searched from GO Database (http://www. geneontology. org/). P-values for differentially expressed genes in all of the GO categories were calculated, and the threshold of significance was defined as $P<0.05$. Differentially expressed mRNAs were subjected to pathway analysis through KEGG (http://www.genome. jp/kegg/). Signaling pathways were analyzed on the basis of significance level with $P<0.05$ as the threshold.

\section{Co-expression network}

Gene co-expression networks were constructed according to the normalized signal intensity of individual genes to identify interactions among genes and lncRNAs [29]. Data were preprocessed by considering the median gene expression value of all transcripts expressed from the same coding gene but without providing a special treatment of the lncRNA expression value. These data were then screened for differentially expressed IncRNAs and mRNAs and removed from the dataset. For each analyzed pair of
Table 1. Verification of gene expression changes by qRT-PCR. Primers used in this paper

\begin{tabular}{|c|c|c|}
\hline Primer Name & Sequence ( 5 ' to $3^{\prime}$ ] & Lengths (bp) \\
\hline \multirow[t]{2}{*}{ NONMMUT033847 } & FW AGCAGGGCAGGCTACTCACA & \multirow{2}{*}{171} \\
\hline & Rev GCCACCGTACCATGAAGCAC & \\
\hline \multirow[t]{2}{*}{ NONMMUT070811 } & FW GAGGGGTTACTTGGCTGTGGA & \multirow{2}{*}{190} \\
\hline & Rev GCTACGAACGGTTTCAGAATTTGT & \\
\hline \multirow[t]{2}{*}{ NONMMUT015327.2 } & FW CAGTGTGGGGAGCATGTGAAC & \multirow{2}{*}{138} \\
\hline & Rev TCCGAGATGCCTCTACTCAAGAC & \\
\hline \multirow[t]{2}{*}{ Dnajb1 } & FW GGACCAGACCTCGAACAACATT & \multirow{2}{*}{222} \\
\hline & Rev GGGACTTTCCGCCGCAT & \\
\hline \multirow[t]{2}{*}{ Egr2 } & FW CGGTGACCATCTTCCCCAAT & \multirow{2}{*}{138} \\
\hline & Rev GAGCGAAGCTACTCGGATACG & \\
\hline \multirow[t]{2}{*}{ Hba-a1 } & Fw CCTCACTTTGATGTAAGCCACG & \multirow{2}{*}{272} \\
\hline & Rev GTGCTCACAGAGGCAAGGAAT & \\
\hline \multirow[t]{2}{*}{ Tnfsf9 } & FW AGGAGGAGAGAAAGTTCCG & \multirow{2}{*}{214} \\
\hline & Rev GTAGGTCGTCCATGAAGC & \\
\hline \multirow[t]{2}{*}{ Cxcl2 } & FW GTAGTTGGAAGGTGATGCATTT & \multirow{2}{*}{224} \\
\hline & Rev CCCTGCTGACAATAAAGACAGAG & \\
\hline \multirow[t]{2}{*}{ IL-1 $\beta$} & FW GTTCTCTGAGAAATGGGAGC & \multirow{2}{*}{143} \\
\hline & Rev CTGGTCATCATCACAGAAGG & \\
\hline \multirow[t]{2}{*}{ Actin } & Fw CGTTGACATCCGTAAAGACCTC & \multirow{2}{*}{159} \\
\hline & Rev ACAGAGTACTTGCGCTCAGGAG & \\
\hline
\end{tabular}




\section{Cellular Physiology Cell Physiol Biochem 2017;42:416-426

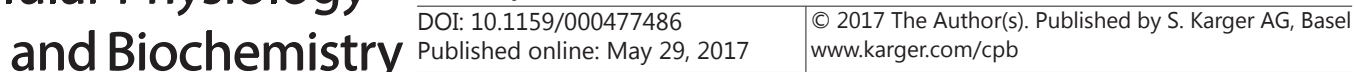 \\ Ma et al.: LncRNA Expression Profile Analysis of Obesity with Folic Acid Supplement}

genes, Pearson correlation was calculated and pairs (only lncRNA-mRNA) with significant correlations were selected to construct the network [30]. The strongest correlations ( 0.99 or greater) were included in these renderings to prepare a visual representation. In this representation, each gene corresponded to a node and, a strong correlation, either positive or negative, was determined when two genes were connected by an edge. Co-expression networks were obtained by using Cytoscape. The degree and normalized degree were calculated to examine the topological property of this graph. A degree was defined as the number of directly linked neighbors [18]. The normalized degree was calculated by dividing the maximum degree in the same network to reduce the difference between individuals.

\section{Statistical Analysis}

Data were expressed as mean \pm standard error of mean. Differences between groups were initially analyzed with Student's t-test or ANOVA and then with Newman-Keuls multiple comparison test by using GraphPad (GraphPad Prism version 5.0 for Windows, GraphPad). A value of $P<0.05$ was considered statistically significant.

\section{Results}

Body weight, glucose tolerance and plasma adipokine levels of the three mouse groups

After 12 weeks of treatment, changes in body weight between the HFD and HFDF groups were closely similar. And the body weight of HFD group were significant increased than that of SD group since 3 weeks of treatment $(P<0.05$, Fig. 1A). However, glucose tolerance test were significant improved, indicative of improved glucose tolerance $(P<0.05$, Fig. 1B). Plasma leptin levels in the HFD group were remarkably higher than those in the HFDF group, and no significant differences in insulin, resistin, and PAI- $1(P<0.05$, Fig. $1 C)$.

\section{Differentially expressed IncRNAs}

A genome-wide analysis of lncRNA and mRNA expression was performed to profile differentially expressed IncRNAs and mRNAs in FA intake and matching obesity. Hierarchical clustering was analyzed according to the lncRNAs and mRNAs expression values in the microarray (Fig. 2). The microarray data revealed that 220 genes were differentially expressed between the two groups. Of these genes, 122 lncRNAs were up-regulated and 98 lncRNAs were down-regulated (fold change $\geq 1.5, P<0.05$ ). Hierarchical clustering analysis was conducted to arrange specimens into groups according to their expression levels, and the top 20 differentially expressed IncRNAs are listed in Table 2.

\section{Differentially expressed $m R N A s$}

A total of 101 mRNAs were differentially expressed between the two groups by using the same criteria of lncRNAs. Of these genes, 88 mRNAs were up-regulated and 13 mRNAs

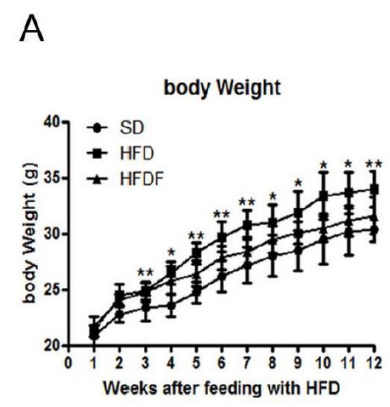

B

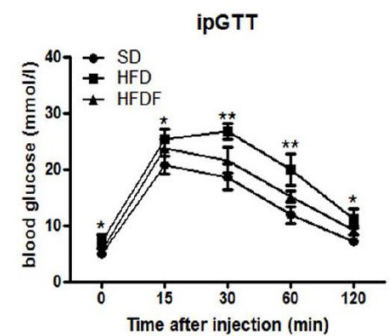

C

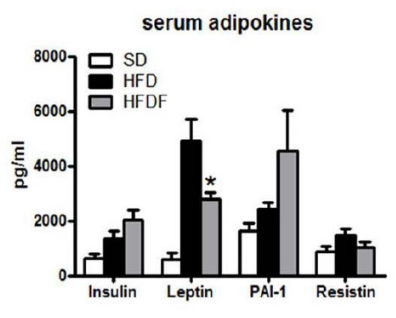

Fig. 1. The body weight, glucose tolerance testing and serum adipokine levels in SD, HFD and HFDF group. (A) the body weight changes in standard diet, high-fat diet or high-fat diet plus FA intake fed mice during 12-week treatment. (B) glucose tolerance testing and (C) the serum adipokine levels are tested at the end of experiment. Data are presented asmeans \pm SEM, $\mathrm{n}=15$. ${ }^{*} P<0.05{ }^{*} * P<0.01$ vs HFD group. 


\section{Cellular Physiology \begin{tabular}{ll|l} 
and Biochemistry Published online: May 29, 2017 & $\begin{array}{l}\text { (c) } 2017 \text { The Author(s). Published by S. Karger AG, Basel } \\
\text { www.karger.com/cpb }\end{array}$ \\
\hline
\end{tabular}

A

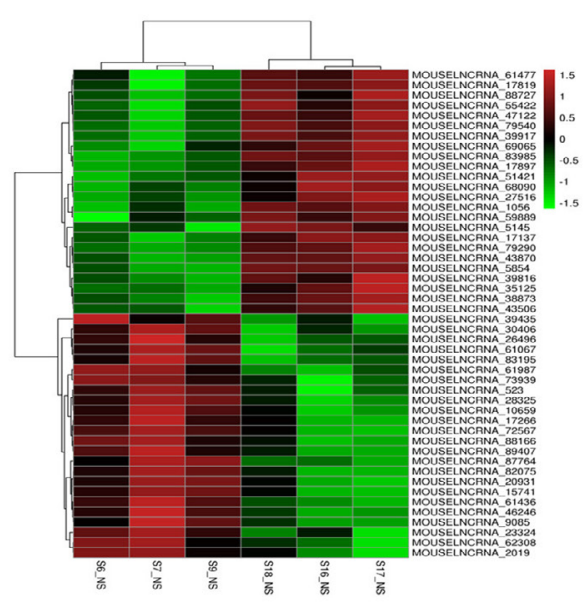

B

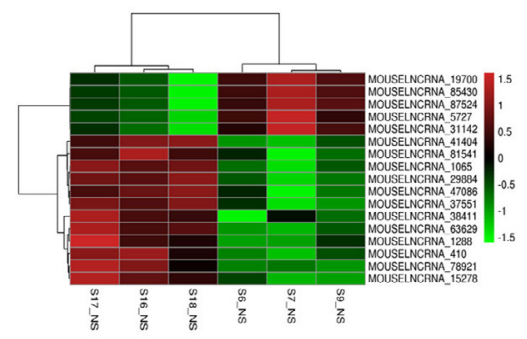

Fig. 2. Profiles of differentially expressed genes in HFDF compared to HFD group. (A) Differentially expressed IncRNAs and (B) differentially expressed mRNAs were subjected to hierarchical clustering. Red color indicates high relative expression and green color indicates low relative expression. $P<0.05, \mathrm{FC} \geq 2$.

Table 2. Top 20 significantly differentially expressed lncRNAs

\begin{tabular}{lllllll}
\hline RNA Accession & Gene Symbol & Chr & Start & End & $P$ values & Fold change \\
\hline NR_038032 & Gm15663 & chr10 & 105574550 & 105583870 & 0.000973306 & 1.899707836 \\
NONMMUT059061 & NONMMUG036701 & chr6 & 128964191 & 128967252 & 0.001433567 & 2.151778543 \\
NR_045328 & A330009N23Rik & chr15 & 101221190 & 101225186 & 0.001853522 & 1.657590951 \\
NONMMUT000870 & NONMMUG000588 & chr1 & 52185063 & 52186843 & 0.002636463 & 1.555908649 \\
NONMMUT051427 & NONMMUG031897 & chr5 & 21951858 & 21952499 & 0.003097323 & 2.002607194 \\
NONMMUT029386 & NONMMUG018157 & chr17 & 34981862 & 34983981 & 0.003473757 & 1.551636372 \\
NONMMUT050450 & NONMMUG031254 & chr4 & 144131848 & 144133881 & 0.00351878 & 2.005182058 \\
NONMMUT065604 & NONMMUG040577 & chr8 & 49706193 & 49707681 & 0.004088748 & 2.111843634 \\
NONMMUT020986 & NONMMUG013027 & chr14 & 55481590 & 55484028 & 0.004141571 & 0.652487258 \\
NONMMUT036501 & NONMMUG022457 & chr2 & 29496511 & 29500548 & 0.004230885 & 0.652489439 \\
NONMMUT052591 & NONMMUG032652 & chr5 & 67260340 & 67261262 & 0.004268772 & 2.269280861 \\
ENSMUST00000104403 & ENSMUSG00000077591 & chr10 & 45268603 & 45268731 & 0.004354266 & 3.081275478 \\
ENSMUST00000145794 & ENSMUSG00000085282 & chr10 & 105574559 & 105583874 & 0.0051675 & 1.587201826 \\
NONMMUT005687 & NONMMUG003666 & chr10 & 56971989 & 56982231 & 0.005868971 & 1.710593567 \\
NONMMUT037692 & NONMMUG023266 & chr2 & 68135664 & 68136612 & 0.005954769 & 1.995954743 \\
NONMMUT053714 & NONMMUG033329 & chr5 & 109874406 & 109875259 & 0.007239241 & 0.601696143 \\
NR_102275 & AI839979 & chr5 & 31569591 & 31571397 & 0.007472296 & 2.104869272 \\
NONMMUT050442 & NONMMUG031247 & chr4 & 143685016 & 143687052 & 0.007498551 & 1.949747508 \\
NONMMUT048568 & NONMMUG030140 & chr4 & 108052367 & 108055221 & 0.007836593 & 0.644541465 \\
ENSMUST00000192441 & ENSMUSG00000102950 & chr1 & 181986336 & 181990204 & 0.008368272 & 1.556936786 \\
\hline
\end{tabular}

were down-regulated (fold change $\geq 1.5, P<0.05$ ). The first 20 differentially expressed mRNAs are listed in Table 3.

Function analysis of differentially expressed genes

Differentially expressed mRNAs were subjected to GO enrichment analysis to identify GOs with higher confidence. Enrichment indicates the significance of a specific function. As enrichment increases, the corresponding function is more specific and thus helps identify GOs with a more concrete functional description in experiments. These functional analyses were performed for all of the differentially expressed mRNAs. GOs associated with differentially expressed transcripts were "negative regulation of transcription from RNA polymerase II promoter," "multicellular organismal development," and "transport." Gene ontology analysis which primarily related to transport, cell development, metabolic process are shown in Fig. $3 \mathrm{~A}$. 
Table 3. Top 20 significantly differentially expressed mRNAs

\begin{tabular}{|c|c|c|c|c|c|c|c|}
\hline RNA Accession & Gene Symbol & Gene Desciption & $\mathrm{Chr}$ & Start & End & $P$ values & Fold change \\
\hline NM_020275 & Tnfrsfiob & tumor necrosis factor receptor superfamily $\% 2 \mathrm{C}$ member $10 \mathrm{~b}$ & chr14 & 69767471 & 69784411 & 0.000760301 & 1.630787619 \\
\hline NM_026232 & Slc25a30 & solute carrier family $25 \% 2 \mathrm{C}$ member 30 & chr14 & 75761998 & 75787037 & 0.001119217 & 1.520735231 \\
\hline NM_080510 & Trim69 & tripartite motif-containing 69 & chr2 & 122160699 & 122179027 & 0.004089418 & 2.484901038 \\
\hline NM_001011861 & Olfr331 & olfactory receptor 331 & chr11 & 58501597 & 58502554 & 0.004497991 & 1.602501561 \\
\hline NM_138952 & Ripk2 & receptor (TNFRSF)-interacting serine-threonine kinase 2 & chr4 & 16123374 & 16163498 & 0.005140857 & 1.541011315 \\
\hline NM_029363 & 2010109A12Rik & RIKEN CDNA 2010109A12 gene & chr5 & 93206517 & 93213474 & 0.005303734 & 1.623702768 \\
\hline NM_175493 & Gpr68 & G protein-coupled receptor $68 \% 2 \mathrm{C}$ transcript variant 1 & chr12 & 100876681 & 100908198 & 0.006847167 & 2.364599468 \\
\hline NM_008690 & Nfkbie & $\begin{array}{l}\text { nuclear factor of kappa light polypeptide gene enhancer in B cells } \\
\text { inhibitor } \% 2 \mathrm{C} \text { epsilon }\end{array}$ & chr17 & 45555699 & 45563168 & 0.006930452 & 1.823944579 \\
\hline NM_001033156 & Fbxo33 & F-box protein 33 & chr12 & 59200654 & 59219483 & 0.007867056 & 1.518140761 \\
\hline NM_138630 & Arhgap4 & Rho GTPase activating protein $4 \% 2 \mathrm{C}$ transcript variant 1 & $\operatorname{chr} X$ & 73894351 & 73911298 & 0.008836336 & 1.551066197 \\
\hline NM_001287176 & Alpl & alkaline phosphatase $\% 2 \mathrm{C}$ liver/bone $/$ kidney $\% 2 \mathrm{C}$ transcript variant 3 & chr4 & 137741730 & 137769820 & 0.008869479 & 1.519689763 \\
\hline NM_001270722 & Gm21319 & predicted gene $\% 2 \mathrm{C} 21319$ & chr12 & 87772424 & 87775755 & 0.009050529 & 1.520749363 \\
\hline NM_010479 & Hspa1a & heat shock protein $1 \mathrm{~A}$ & chr17 & 34969358 & 34972156 & 0.009735401 & 8.220655127 \\
\hline NM_028657 & Mfsd12 & major facilitator superfamily domain containing 12 & $\operatorname{chr} 10$ & 81357569 & 81364035 & 0.009809235 & 1.585460094 \\
\hline NM 018808 & Dnajb1 & Dna] (Hsp40) homolog\%2C subfamily B\%2C member 1 & chr8 & 83608174 & 83611903 & 0.009822239 & 2.799157241 \\
\hline NM_001291066 & Adam 8 & a disintegrin and metallopeptidase domain $8 \% 2 \mathrm{C}$ transcript variant 2 & chr7 & 139978937 & 139992509 & 0.009862383 & 1.578144923 \\
\hline NM_009992 & Cyp1a1 & $\begin{array}{l}\text { cytochrome } \mathrm{P} 450 \% 2 \mathrm{C} \text { family } 1 \% 2 \mathrm{C} \text { subfamily a } \% 2 \mathrm{C} \text { polypeptide } 1 \% 2 \mathrm{C} \\
\text { transcript variant } 1\end{array}$ & $\operatorname{chr} 9$ & 57687927 & 57703824 & 0.010123204 & 1.747740192 \\
\hline NM_001122640 & $\mathrm{A}$ & Rho GTPase activating protein $17 \% 2 \mathrm{C}$ transcript variant 2 & chl & 79148 & 915 & 4411 & 6218 \\
\hline NM_172462 & Zfp11 & zinc finger protein 11 & chr5 & 129654594 & 129670088 & 0.010850417 & 1.633307005 \\
\hline NM_026209 & Saysd1 & SAYSVFN motif domain containing 1 & chr14 & 20075635 & 20083172 & 0.011085833 & 1.952614937 \\
\hline
\end{tabular}

Fig. 3. Gene ontology analysis and pathway analysis of differentially expressed unigenes. (A) The top 10 gene ontology that related to transport, cell development, metabolic process analysis of differentially expressed unigenes. (B) The top 10 pathway which related to inflammation, metabolism and differentiation analysis of all differentially expressed unigenes.

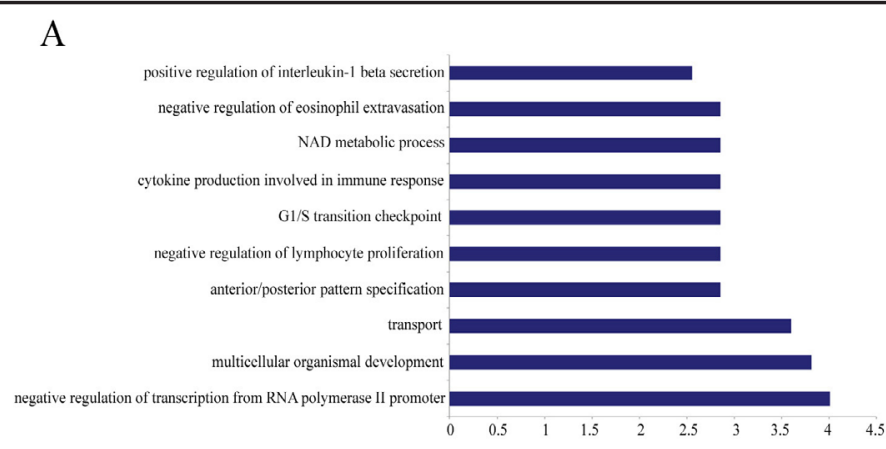

B

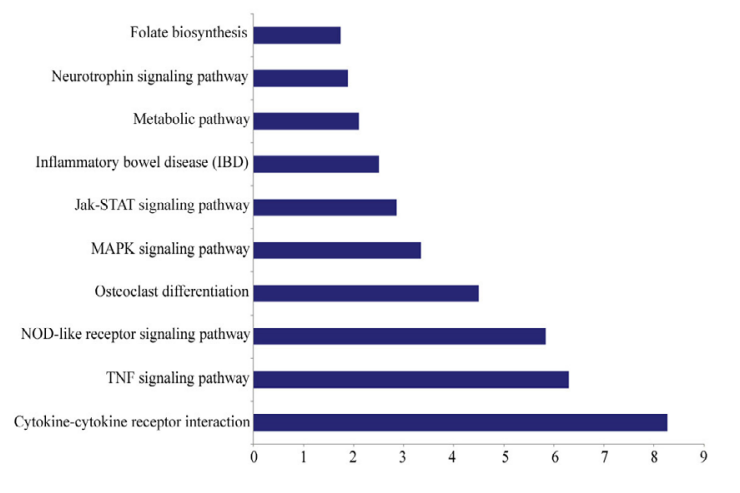

Pathway analysis indicated that 36 pathways were significantly enriched among the differentially expressed transcripts. Many of these pathways, such as "Cytokine-cytokine receptor interaction pathway," "Osteoclast differentiation pathway," "MAPK signaling pathway," "Metabolic pathways," and "Folate biosynthesis," were linked to inflammation, energy metabolism, and cell differentiation. The pathways which related to inflammation, metabolism and differentiation are shown in Fig. 3B.

Co-expression analysis between differentially expressed IncRNAs and coding genes in HFD and HFDF

Pearson correlation was calculated and general coding-noncoding gene co-expression networks were constructed in each of the HFD and HFDF groups with the differentially expressed lncRNAs and mRNAs from this study to determine the transcriptional regulatory relationship. A total of 432 co-expression edges connecting 136 nodes, with 91 coding 
Table 4. Top 15 lncRNAs and mRNAs with largest degree differences in HFDF co-expression network compared with HFD groups

\begin{tabular}{lcclll}
\hline Gene & HFD egree & HFDF Degree & abs_network diffence & style & regulation \\
\hline Dnajb1 & 6 & 0 & 0.75 & coding & up \\
NONMMUT033847 & 2 & 9 & 0.75 & nocoding & down \\
NONMMUT070811 & 0 & 6 & 0.666667 & nocoding & down \\
NONMMUT015327 & 7 & 2 & 0.652778 & nocoding & down \\
Egr2 & 6 & 1 & 0.638889 & coding & up \\
ENSMUST00000124376 & 3 & 9 & 0.625 & nocoding & up \\
Gem & 7 & 3 & 0.541667 & coding & up \\
Hba-a1 & 7 & 3 & 0.541667 & coding & down \\
Gm14548 & 2 & 7 & 0.527778 & coding & up \\
NONMMUT004166 & 5 & 1 & 0.513889 & nocoding & down \\
NONMMUT022094 & 3 & 8 & 0.513889 & nocoding & up \\
Tectb & 5 & 1 & 0.513889 & coding & up \\
Cd300lb & 4 & 0 & 0.5 & coding & up \\
Gm13288 & 4 & 0 & 0.5 & coding & up \\
Spaca3 & 4 & 0 & 0.5 & coding & up \\
\hline
\end{tabular}

Fig. 4. Coding-no-coding gene co-expression network was constructed based on the correlation analysis between the differentially expressed IncRNAs and mRNAs between (A) HFD and (B) HFDF group. In the network, Genes colored in red are up-regulated, genes colored in green are down-regulated and genes denoted a blue ring encode lncRNAs. Grey solid lines indicate correlation of genes. Node size represents the node degrees.

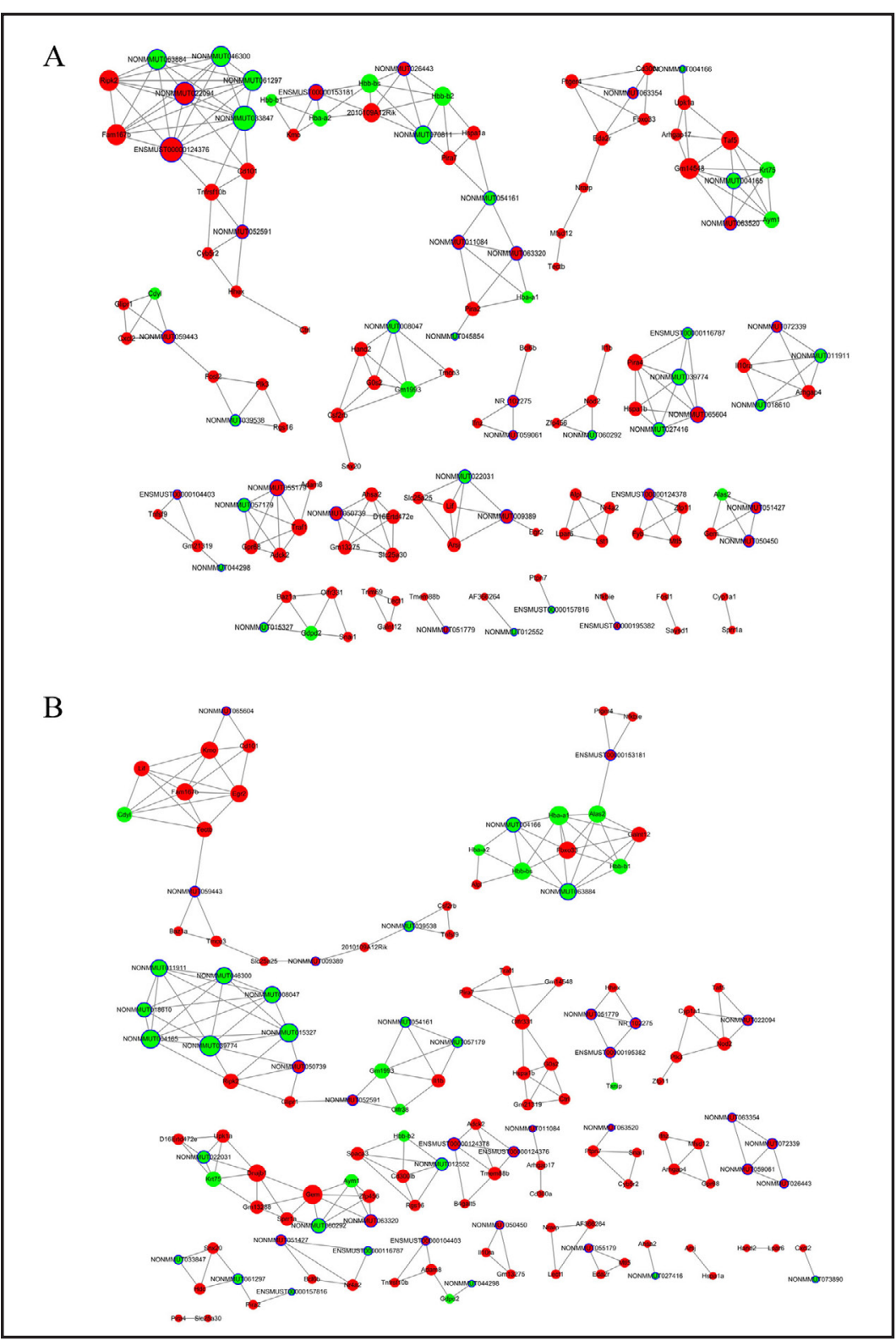

genes and 45 lncRNAs, were found in the FA intake network (Fig. 4B), whereas 464 coexpression edges connecting 135 nodes, with 89 coding genes and 46 lncRNAs, were found in the control obesity network (Fig. 4A). According to the degree analysis, Dnajb1, Egr2, Hba-a1, NONMMUT033847, NONMMUT070811, and NONMMUT015327 yielded the largest 


\section{Cellular Physiology Cell Physiol Biochem 2017;42:416-426

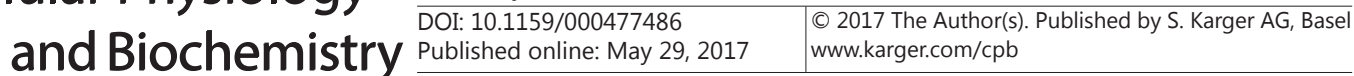 \\ Ma et al.: LncRNA Expression Profile Analysis of Obesity with Folic Acid Supplement}

Fig. 5. LncRNAs and mRNAs in HFD and HFDF of mice hearts were validated by qRT-PCR. (A) 6 IncRNAs and mRNAs which analyzed by co-expression were validated by qRT-PCR. (B) 3 inflammatory genes were validated by qRT-PCR. The height of the columns in the figure represents the expression level relative to GAPDH. The data are expressed as mean SEM. ${ }^{*} P<0.05$, ${ }^{* *} P<0.01$ vs HFD group.

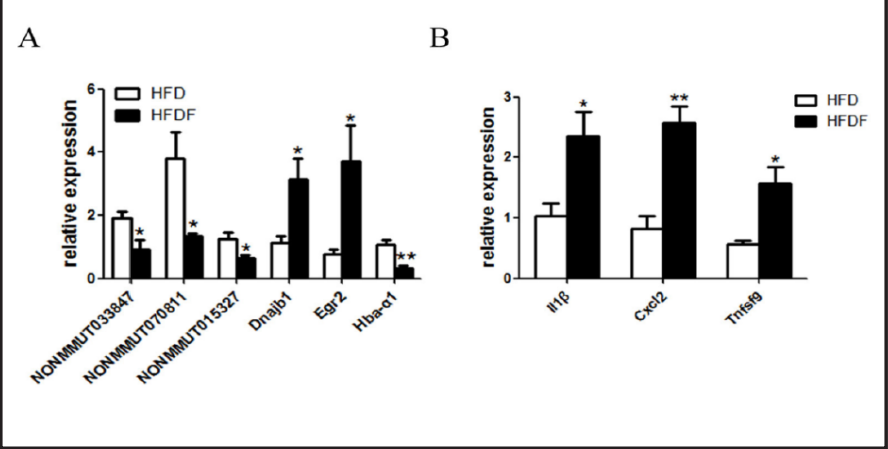

changes in the degree within the network. The first 15 lncRNAs and mRNAs with the largest changes in the degree between HFD and HFDF are shown in Table 4. These genes primarily participate in cytokine-cytokine receptor interaction, osteoclast differentiation, MAPK signaling pathway, Jak-STAT signaling pathway, neurotrophin signaling pathway, and folate biosynthesis. These results indicate that the lncRNAs in the network likely perform similar functions and thus might play a vital role in the molecular regulation of obesity.

\section{QRT-PCR validation}

NONMMUT033847, NONMMUT070811, NONMMUT015327, Egr2, Dnajb1, and Hba-a1 were chosen to validate our microarray results (Fig. 5A). The relative genes involved in the cytokine-cytokine receptor interaction pathway (Il1 $\beta$, Cxcl2, and Tnfsf9) were also detected through qRT-PCR (Fig. 5B). QRT-PCR results are consistent with microarray findings.

\section{Discussion}

In this study, the genome-wide expression profile of IncRNAs and mRNAs in the heart of mice fed with SD and HFD were investigated through microarray. A total of 220 lncRNAs, including 122 up-regulated and 98 down-regulated were identified to be differentially expressed between the two groups of mice. Simultaneously, 101 differentially expressed protein coding mRNAs from the same chip were also identified, including 88 up-regulated and 13 down-regulated mRNAs. The differences in the expression of IncRNAs and mRNAs detected through qRT-PCR were consistent with those observed through microarray.

Cardio-metabolic diseases are characterized as a combination of multiple risk factors of cardiovascular diseases (CVD) and metabolic diseases, including diabetes mellitus, dyslipidemia, hypertension, and abdominal obesity [19]. Childhood obesity is a chronic and complex metabolic disorder, which is associated with a high risk of various medical and psychosocial consequences [20]. CVD and type 2 diabetes mellitus are the most common preventable complications of childhood obesity. The presence of biochemical indicators, such as insulin resistance, hyperinsulinemia, and hyperhomocysteinemia, are associated with the early phase of these conditions, and proper interventions can prevent the development of complications [21,22].

The role of FA in metabolic health has been reported. Silva et al. revealed that FA deficiencies are found more frequently among individuals subjected to gastric bypass than gastric banding of bariatric techniques [23]. In an urban low-income prospective birth cohort, maternal plasma folate concentrations exhibit an L-shaped association with child overweight or obesity sufficient folate concentrations provide beneficial effects on individuals, especially obese mothers [24]. Dehkordi demonstrated that FA in two examined doses can be a safe and effective supplement for obese children to reduce homocysteine levels and insulin resistance; consequently, FA can prevent obesity-related complications, including cardiovascular and metabolic disorders [4]. The homocysteine-reducing effects of FA supplementation are observed in obese children [25]. Inflammation is increased in 


\section{Cellular Physiology Cell Physiol Biochem 2017;42:416-426 \\ \begin{tabular}{l|l} 
DOI: 10.1159/000477486 & Ond Biochemistry 2017 The Author(s). Published by S. Karger AG, Basel \\
www.karger.com/cpb
\end{tabular} \\ Ma et al.: LncRNA Expression Profile Analysis of Obesity with Folic Acid Supplement}

rats fed with high-fat-adequate FA (HF-AFA), and this increase is associated with impaired glucose tolerance compared with HF-EFA-fed rats. FA induces the PPAR $\gamma$ expression and triglyceride accumulation in 3T3-L1 cells [26]. FA may influence the pathogenesis of CHDs through other more complex pathways, including epigenetic mechanisms responsible for transgenerational effects [27]. Epigenetic mechanisms are possibly implicated in this process because the beneficial effects of FA fortification in reducing the prevalence of CHDs at birth may require more than one generation to become fully apparent [27]. In a Hungarian randomized trial, the birth prevalence of congenital cardiovascular anomalies is lower among women prescribed with periconceptional multivitamins, including FA, and trace element supplementation than among women given with supplemental trace elements only [28]. Our results demonstrated that NONMMUT033847, NONMMUT070811, and NONMMUT015327 were down-regulated in the HFDF group. QRT-PCR results validated our microarray data, which indicated that identified lncRNAs might play an important role in improving the cardiovascular functions during obesity.

Considering the importance of the cytokine-cytokine receptor interaction pathway, we focused on Csf2rb, Cxcl2, Eda2r, Il10ra, Il1 $\beta$, Lif, Tnfrsf10b, and Tnfsf9. These genes are involved in the regulation of cell development, activation, growth, and motility. Nehete et al. observed the plasma-circulating levels of pro-inflammatory Th-1 cytokines, interferon gamma, interleukin-6, interleukin-12p40, tumor necrosis factor, soluble CD40 ligand, and interleukin- $1 \beta$, and those of anti-inflammatory Th-2 cytokines, interleukin- 4 , interleukinRA, interleukin-10, and interleukin-13 increase in overweight and obese chimpanzees [29]. In cytokines and chemokines in WBCs, TNF-SF5, 7, and 9 and CCL 8 and 10 are significantly higher in children with type 1 diabetes than in healthy children [30]. Chemokine ligand-2 (CXCL2), a WAT, produces up-regulated chemokines in obesity. Activated neutrophils in obesity may influence the functions of visceral WAT endothelial cells and contribute to WAT inflammation [31]. Our PCR results indicated that Il1 $\beta$, CXCL2, and Tnfsf9 are significantly higher in the HFDF group than in the HFD group. Hba-a1 was down-regulated and Dnajb1 and Egr2 were up-regulated in the HFDF group. QRT-PCR results validated our microarray data.

This study was limited by the following. (i) GO and pathway analyses are required to further investigate the relationships among noncoding RNAs, coding RNAs, and proteins. (ii) LncRNAs and mRNAs validated by qPCR should be further tested on cell level.

In summary, this study identified the expression patterns of lncRNAs and mRNAs in the heart of mice fed with HFD and HFDF. LncRNAs were detected as a potential regulatory factor of obesity most likely through inflammation, energy metabolism, and cell differentiation. Further work should be performed to understand the biological functions and molecular mechanisms of specific lncRNAs implicated in obesity.

\section{Acknowledgments}

This work was supported by the National Natural Science Foundation of China (81400365), CAMS Central Public Welfare Scientific Research Institute Basal Research Expenses to HW (2016ZX310182-3), CAMS Initiative for Innovative Medicine (CAMS-I2M).

\section{Disclosure Statement}

None of the authors have any potential conflicts of interest associated with this research.

\section{References}

\footnotetext{
1 Huby AC, Antonova G, Groenendyk J, Gomez-Sanchez CE, Bollag WB, Filosa JA, Belin de Chantemele EJ: Adipocyte-derived hormone leptin is a direct regulator of aldosterone secretion, which promotes endothelial dysfunction and cardiac fibrosis. Circulation 2015;132:2134-2145.
} 


\section{Cellular Physiology Cell Physiol Biochem 2017;42:416-426

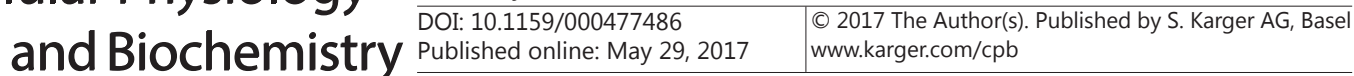 \\ Ma et al.: LncRNA Expression Profile Analysis of Obesity with Folic Acid Supplement}

2 Bouchard C: Gene-environment interactions in the etiology of obesity: Defining the fundamentals. Obesity DOI: $10.1038 /$ oby.2008.528.

3 McCarthy MI: Genomics, type 2 diabetes, and obesity. N Engl J Med 2010;363:2339-2350.

4 Dehkordi EH, Sedehi M, Shahraki ZG, Najafi R: Effect of folic acid on homocysteine and insulin resistance of overweight and obese children and adolescents. Adv Biomed Res 2016;5:88.

5 Liu S, Joseph KS, Luo W, Leon JA, Lisonkova S, Van den Hof M, Evans J, Lim K, Little J, Sauve R, Kramer MS, Canadian Perinatal Surveillance S: Effect of folic acid food fortification in canada on congenital heart disease subtypes. Circulation 2016;134:647-655.

-6 Alsaggar M, Mills M, Liu D: Interferon beta overexpression attenuates adipose tissue inflammation and high fat diet-induced obesity and maintains glucose homeostasis. Gene Ther 2017;24:60-66.

7 Saini A, Sharples AP, Al-Shanti N, Stewart CE: Omega-3 fatty acid epa improves regenerative capacity of mouse skeletal muscle cells exposed to saturated fat and inflammation. Biogerontology 2017;18:109-129. Cildir G, Akincilar SC, Tergaonkar V: Chronic adipose tissue inflammation: All immune cells on the stage. Trends Mol Med 2013;19:487-500.

-9 Brestoff JR, Artis D: Immune regulation of metabolic homeostasis in health and disease. Cell 2015;161:146160.

10 Ponting CP, Oliver PL, Reik W: Evolution and functions of long noncoding rnas. Cell 2009;136:629-641.

11 Mitra SA, Mitra AP, Triche TJ: A central role for long non-coding rna in cancer. Front Genet 2012;3:17.

12 Perkel JM: Visiting "noncodarnia". BioTechniques 2013;54:303-304.

13 Consortium EP, Birney E, Stamatoyannopoulos JA, Dutta A, Guigo R, Gingeras TR, Margulies EH, Weng Z, Snyder M, Dermitzakis ET, Thurman RE, Kuehn MS, Taylor CM, Neph S, Koch CM, Asthana S, Malhotra A, Adzhubei I, Greenbaum JA, Andrews RM, Flicek P, Boyle PJ, Cao H, Carter NP, Clelland GK, Davis S, Day N, Dhami P, Dillon SC, Dorschner MO, Fiegler H, Giresi PG, Goldy J, Hawrylycz M, Haydock A, Humbert R, James KD, Johnson BE, Johnson EM, Frum TT, Rosenzweig ER, Karnani N, Lee K, Lefebvre GC, Navas PA, Neri F, Parker SC, Sabo PJ, Sandstrom R, Shafer A, Vetrie D, Weaver M, Wilcox S, Yu M, Collins FS, Dekker J, Lieb JD, Tullius TD, Crawford GE, Sunyaev S, Noble WS, Dunham I, Denoeud F, Reymond A, Kapranov P, Rozowsky J, Zheng D, Castelo R, Frankish A, Harrow J, Ghosh S, Sandelin A, Hofacker IL, Baertsch R, Keefe D, Dike S, Cheng J, Hirsch HA, Sekinger EA, Lagarde J, Abril JF, Shahab A, Flamm C, Fried C, Hackermuller J, Hertel J, Lindemeyer M, Missal K, Tanzer A, Washietl S, Korbel J, Emanuelsson O, Pedersen JS, Holroyd N, Taylor R, Swarbreck D, Matthews N, Dickson MC, Thomas DJ, Weirauch MT, Gilbert J, Drenkow J, Bell I, Zhao X, Srinivasan KG, Sung WK, Ooi HS, Chiu KP, Foissac S, Alioto T, Brent M, Pachter L, Tress ML, Valencia A, Choo SW, Choo CY, Ucla C, Manzano C, Wyss C, Cheung E, Clark TG, Brown JB, Ganesh M, Patel S, Tammana H, Chrast J, Henrichsen CN, Kai C, Kawai J, Nagalakshmi U, Wu J, Lian Z, Lian J, Newburger P, Zhang X, Bickel P, Mattick JS, Carninci P, Hayashizaki Y, Weissman S, Hubbard T, Myers RM, Rogers J, Stadler PF, Lowe TM, Wei CL, Ruan Y, Struhl K, Gerstein M, Antonarakis SE, Fu Y, Green ED, Karaoz U, Siepel A, Taylor J, Liefer LA, Wetterstrand KA, Good PJ, Feingold EA, Guyer MS, Cooper GM, Asimenos G, Dewey CN, Hou M, Nikolaev S, Montoya-Burgos JI, Loytynoja A, Whelan S, Pardi F, Massingham T, Huang H, Zhang NR, Holmes I, Mullikin JC, Ureta-Vidal A, Paten B, Seringhaus M, Church D, Rosenbloom K, Kent WJ, Stone EA, Program NCS, Baylor College of Medicine Human Genome Sequencing C, Washington University Genome Sequencing C, Broad I, Children's Hospital Oakland Research I, Batzoglou S, Goldman N, Hardison RC, Haussler D, Miller W, Sidow A, Trinklein ND, Zhang ZD, Barrera L, Stuart R, King DC, Ameur A, Enroth S, Bieda MC, Kim J, Bhinge AA, Jiang N, Liu J, Yao F, Vega VB, Lee CW, Ng P, Shahab A, Yang A, Moqtaderi Z, Zhu Z, Xu X, Squazzo S, Oberley MJ, Inman D, Singer MA, Richmond TA, Munn KJ, Rada-Iglesias A, Wallerman O, Komorowski J, Fowler JC, Couttet P, Bruce AW, Dovey OM, Ellis PD, Langford CF, Nix DA, Euskirchen G, Hartman S, Urban AE, Kraus P, Van Calcar S, Heintzman N, Kim TH, Wang K, Qu C, Hon G, Luna R, Glass CK, Rosenfeld MG, Aldred SF, Cooper SJ, Halees A, Lin JM, Shulha HP, Zhang X, Xu M, Haidar JN, Yu Y, Ruan Y, Iyer VR, Green RD, Wadelius C, Farnham PJ, Ren B, Harte RA, Hinrichs AS, Trumbower H, Clawson H, Hillman-Jackson J, Zweig AS, Smith K, Thakkapallayil A, Barber G, Kuhn RM, Karolchik D, Armengol L, Bird CP, de Bakker PI, Kern AD, LopezBigas N, Martin JD, Stranger BE, Woodroffe A, Davydov E, Dimas A, Eyras E, Hallgrimsdottir IB, Huppert J, Zody MC, Abecasis GR, Estivill X, Bouffard GG, Guan X, Hansen NF, Idol JR, Maduro VV, Maskeri B, McDowell JC, Park M, Thomas PJ, Young AC, Blakesley RW, Muzny DM, Sodergren E, Wheeler DA, Worley KC, Jiang H, Weinstock GM, Gibbs RA, Graves T, Fulton R, Mardis ER, Wilson RK, Clamp M, Cuff J, Gnerre S, Jaffe DB, Chang JL, Lindblad-Toh K, Lander ES, Koriabine M, Nefedov M, Osoegawa K, Yoshinaga Y, Zhu B, de Jong PJ: 


\section{Cellular Physiology Cell Physiol Biochem 2017;42:416-426

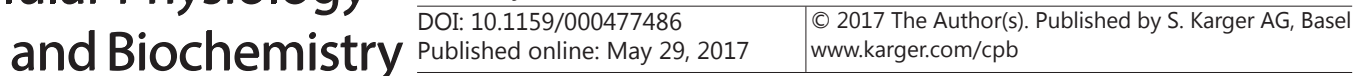 \\ Ma et al.: LncRNA Expression Profile Analysis of Obesity with Folic Acid Supplement}

Identification and analysis of functional elements in $1 \%$ of the human genome by the encode pilot project. Nature 2007;447:799-816.

14 Tseng YY, Moriarity BS, Gong W, Akiyama R, Tiwari A, Kawakami H, Ronning P, Reuland B, Guenther K, Beadnell TC, Essig J, Otto GM, O'Sullivan MG, Largaespada DA, Schwertfeger KL, Marahrens Y, Kawakami Y, Bagchi A: Pvt1 dependence in cancer with myc copy-number increase. Nature 2014;512:82-86.

15 Sun L, Goff LA, Trapnell C, Alexander R, Lo KA, Hacisuleyman E, Sauvageau M, Tazon-Vega B, Kelley DR, Hendrickson DG, Yuan B, Kellis M, Lodish HF, Rinn JL: Long noncoding rnas regulate adipogenesis. Proc Natl Acad Sci U S A 2013;110:3387-3392.

16 Hacisuleyman E, Goff LA, Trapnell C, Williams A, Henao-Mejia J, Sun L, McClanahan P, Hendrickson DG, Sauvageau M, Kelley DR, Morse M, Engreitz J, Lander ES, Guttman M, Lodish HF, Flavell R, Raj A, Rinn JL: Topological organization of multichromosomal regions by the long intergenic noncoding rna firre. Nat Struct Mol Biol 2014;21:198-206.

17 Sun J, Ruan Y, Wang M, Chen R, Yu N, Sun L, Liu T, Chen H: Differentially expressed circulating lncrnas and mrna identified by microarray analysis in obese patients. Sci Rep 2016;6:35421.

18 Barabasi AL, Oltvai ZN: Network biology: Understanding the cell's functional organization. Nat Rev Genet 2004;5:101-113.

19 Dechamethakun S, Muramatsu M: Long noncoding rna variations in cardiometabolic diseases. J Hum Genet 2017;62:97-104.

20 Daniels SR: Complications of obesity in children and adolescents. Int J Obes (Lond) DOI: 10.1038/ijo. 2009.20.

21 Freedman DS, Mei Z, Srinivasan SR, Berenson GS, Dietz WH: Cardiovascular risk factors and excess adiposity among overweight children and adolescents: The bogalusa heart study. J Pediatr 2007;150:12-17 e12.

-22 Park SB, Georgiades A: Changes in body composition predict homocysteine changes and hyperhomocysteinemia in korea. J Korean Med Sci 2013;28:1015-1020.

23 Silva RA, Malta FM, Correia MF, Burgos MG: Serum vitamin b12, iron and folic acid deficiencies in obese individuals submitted to different bariatric techniques. Arq Bras Cir Dig DOI: 10.1590/01026720201600 S10016.

24 Wang G, Hu FB, Mistry KB, Zhang C, Ren F, Huo Y, Paige D, Bartell T, Hong X, Caruso D, Ji Z, Chen Z, Ji Y, Pearson C, Ji H, Zuckerman B, Cheng TL, Wang X: Association between maternal prepregnancy body mass index and plasma folate concentrations with child metabolic health. JAMA Pediatr 2016;170:e160845.

25 Iamopas 0, Ratanachu-ek S, Chomtho S: Effect of folic acid supplementation on plasma homocysteine in obese children: A randomized, double-blind, placebo-controlled trial. J Med Assoc Thai 2014;97:S195-204.

-26 Kelly KB, Kennelly JP, Ordonez M, Nelson R, Leonard K, Stabler S, Gomez-Munoz A, Field CJ, Jacobs RL: Excess folic acid increases lipid storage, weight gain, and adipose tissue inflammation in high fat diet-fed rats. Nutrients DOI: 10.3390/nu8100594.

27 Padmanabhan N, Jia D, Geary-Joo C, Wu X, Ferguson-Smith AC, Fung E, Bieda MC, Snyder FF, Gravel RA, Cross JC, Watson ED: Mutation in folate metabolism causes epigenetic instability and transgenerational effects on development. Cell 2013;155:81-93.

-28 Czeizel AE: The primary prevention of birth defects: Multivitamins or folic acid? Int J Med Sci 2004;1:5061.

29 Nehete P, Magden ER, Nehete B, Hanley PW, Abee CR: Obesity related alterations in plasma cytokines and metabolic hormones in chimpanzees. Int J Inflam DOI: 10.1155/2014/856749.

-30 Rosa JS, Mitsuhashi M, Oliver SR, Ogura M, Flores RL, Pontello AM, Galassetti PR: Ex vivo tcr-induced leukocyte gene expression of inflammatory mediators is increased in type 1 diabetic patients but not in overweight children. Diabetes Metab Res Rev 2010;26:33-39.

-31 Rouault C, Pellegrinelli V, Schilch R, Cotillard A, Poitou C, Tordjman J, Sell H, Clement K, Lacasa D: Roles of chemokine ligand-2 ( $\mathrm{cxcl} 2$ ) and neutrophils in influencing endothelial cell function and inflammation of human adipose tissue. Endocrinology 2013;154:1069-1079. 